\title{
Optimization of activated carbon monolith Co3O4-based catalyst for simultaneous SO2/NOx removal from flue gas using response surface methodology
}

\begin{abstract}
Coal combustion is a primary source of acid gases such as sulfur dioxide (SO2) and nitrogen dioxide (NOx); meanwhile, their effects are detrimental to man and the environment. In this work, three different adsorbents were developed by loading $\mathrm{Co} 3 \mathrm{O} 4$ on monolith using pore volume impregnation, deposition precipitation, and hydrothermal methods (HMs) of synthesis. The breakthrough study in the simultaneous SO2 and NOx removal from flue gas revealed that the performance of the adsorbent developed by HM was better than the adsorbents developed by the other methods. Therefore, the characterization analysis and optimization of the variables that affect the adsorption capacity on the best performed adsorbent by response surface methodology were carried out. The model prediction and the experimental results for the adsorption capacity of SO2 are 134.5 and $132.9 \mathrm{mg} / \mathrm{g}$ while 152.1 and $151.6 \mathrm{mg} / \mathrm{g}$ were obtained for NOx. Furthermore, the optimized independent variables comprising amount of adsorbents, airflow rate, and temperature are $1 \mathrm{mg}, 400 \mathrm{~mL} / \mathrm{min}$, and $100^{\circ} \mathrm{C}$. The regression coefficient of 0.9934 for $\mathrm{SO} 2$ and 0.9991 for NOx was obtained which indicates that the interaction between the independent variables and the adsorption capacity of SO2 and NOx is very significant. These results confirmed the suitability of the model for the prediction of the process behavior and the performance of the adsorbent at low temperature with high adsorption capacity emerged as a new finding.
\end{abstract}

Keyword: Combustion; Optimization; Adsorption capacity; Response surface methodology; Coal 